\title{
Emerging Role of Insulin with Incretin Therapies for Management of Type 2 Diabetes
}

Rupa Ahluwalia · Jiten Vora

To view enhanced content go to www.diabetestherapy-open.com Received: March 1, 2011 / Published online: July 21, 2011

(C) The Author(s) 2011. This article is published with open access at Springerlink.com

\section{ABSTRACT}

Type 2 diabetes mellitus (T2DM) is a progressive disease warranting intensification of treatment, as beta-cell function declines over time. Current treatment algorithms recommend metformin as the first-line agent, while advocating the addition of either basal-bolus or premixed insulin as the final level of intervention. Incretin therapy, including incretin mimetics or enhancers, are the latest group of drugs available for treatment of T2DM. These agents act through

Rupa Ahluwalia $(\bowtie)$

Clinical Research Fellow, Department of Diabetes and Endocrinology, The Royal Liverpool and Broadgreen University Hospitals Trust, Prescot Street, Liverpool, United Kingdom. Email: ahluwalia77@gmail.com

Jiten Vora

Consultant Physician and Endocrinologist, Department of Diabetes and Endocrinology, The Royal Liverpool and Broadgreen University Hospitals Trust, Liverpool, United Kingdom

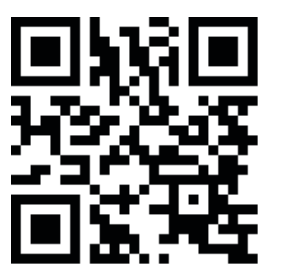

Enhanced content for this article is available on the journal web site: www.diabetestherapy-open.com the incretin axis, are currently recommended as add-on agents either as second- or third-line treatment, without concurrent use of insulin. Given the novel role of incretin therapy in terms of reducing postprandial hyperglycemia, and favorable effects on weight with reduced incidence of hypoglycemia, we explore alternative options for incretin therapy in T2DM management. Furthermore, as some evidence alludes to incretins potentially increasing betacell mass and altering disease progression, we propose introducing these agents earlier in the treatment algorithm. In addition, we suggest the concurrent use of incretins with insulin, given the favorable effects especially in relation to weight gain.

Keywords: incretin therapy; insulin; treatment; type 2 diabetes mellitus

\section{INTRODUCTION}

Type 2 diabetes mellitus (T2DM) is a progressive disease where hyperglycemia occurs when insulin secretion fails to keep pace with insulin resistance. ${ }^{1}$ Therefore, long-term disease management warrants intensification of treatment over time, especially in step 
with declining beta-cell function. ${ }^{2}$ In general, T2DM management commences with lifestyle and dietary advice, with an oral antidiabetic drug (OAD) added if glycemic control remains or becomes suboptimal. Metformin is often recommended as the first-line pharmacotherapy given its well-established efficacy, as well as being weight-neutral and inexpensive. ${ }^{3}$ Metformin can be used in combination with other OADs or insulin, but the traditional OADs (sulfonylureas [SU] and thiazolidinediones [TZD]) and insulin are associated with weight gain, which can compromise patients' ongoing attempts at weight reduction. ${ }^{4}$ At the point of introducing exogenous insulin, depending on national guidelines and individual preferences, OADs other than metformin are often discontinued. The ultimate level of intervention is to add mealtime bolus insulin to, typically, basal insulin plus metformin, or to substitute a premixed insulin regimen.

Over the last few years we have seen the advent of newer drugs in the form of incretinbased therapies. These act primarily by increasing the physiological effects mediated via the hormone glucagon-like peptide-1 (GLP-1), which is secreted along with glucosedependent insulinotropic polypeptide (GIP) by intestinal cells when food is ingested, probably via the neural and endocrine signals associated with feeding. ${ }^{5}$ GLP-1 and GIP have multiple actions that enhance beta-cell response in a glucose-dependent fashion. In T2DM, the incretin response is diminished. ${ }^{6}$ However, the insulinotropic action of GIP is diminished, while that of GLP-1 is preserved, although the secretion of GLP-1 appears to be diminished. ${ }^{7,8}$ Nevertheless, as the tissue sensitivity to GLP-1 is preserved ${ }^{7,9}$ restoration of GLP-1 signal forms the basis of use of GLP-1 receptor agonists as a therapeutic option in T2DM.
Two strategies can restore the GLP-1 signal: inhibiting the enzyme dipeptidyl peptidase- 4 (DPP-4), which rapidly degrades GLP-1 in vivo resulting in increased concentrations of endogenous GLP-1; or using DPP-4 resistant mimetics of GLP-1 (eg, GLP-1 receptor agonists [GLP-1RA]). Drugs acting through the former mechanism are called incretin enhancers, while those with the latter action are classed as incretin mimetics.

The various effects (both insulinotropic and extra-pancreatic) of GLP-1 are well documented. Most of these effects complement the role of incretin therapy in T2DM (Table 1). ${ }^{7,10-17}$ From a blood glucose-lowering point of view, the most appealing property is that GLP-1 glucose dependently increases insulin secretion and suppresses glucagon secretion. Therefore, these actions manifest only in the setting of hyperglycemia. Moreover, counterregulatory responses to hypoglycemia (including glucagon secretion) are fully preserved, even when pharmacological levels of GLP-1 are administered. ${ }^{18}$ In addition, GLP-1 induces satiety and has weight limiting effects, ${ }^{13,19,20}$ along with potential beta-cell sparing actions. ${ }^{15,16}$

DPP-4 inhibitors (incretin enhancers) are orally available drugs that are weight neutral

Table 1. Potential benefit of incretin therapy in the treatment of type 2 diabetes mellitus.

Summary of pancreatic and extra-pancreatic effects of glucagon-like peptide-1 in humans.

Glucose-dependent stimulation of insulin secretion ${ }^{7}$ Glucose-dependent suppression of glucagon secretion ${ }^{7}$ Enhanced glucagon secretion during hypoglycemia ${ }^{10,11}$ Reduced gastrointestinal motility and pancreatic exocrine function $^{12}$

Increased satiety ${ }^{13}$

Improvement of beta-cell function ${ }^{14}$

Increased beta-cell mass with inhibition of beta-cell apoptosis $^{15-17}$ 
with low propensity to cause hypoglycemia. ${ }^{5,21,22}$ Several DPP-4 inhibitors have been developed (e.g. vildagliptin, sitagliptin, saxagliptin).

Currently, two GLP-1RA (incretin mimetics) are clinically available (exenatide, which is administered twice daily [b.i.d.] and liraglutide, administered once daily [o.d.]). Both are given subcutaneously. GLP-1RA reduce hyperglycemia in T2DM either when given as monotherapy or when added to various OAD regimens, and incretin mimetics often achieve weight loss. ${ }^{5}$ Like DPP-4 inhibitors, GLP-1RA carry a low risk of hypoglycemia. Gastrointestinal adverse effects are transient, with nausea generally subsiding by 8 weeks after initiation of exenatide treatment and by 4 weeks after initiation of liraglutide treatment. ${ }^{23}$

Even though incretin enhancers and mimetics act through the same therapeutic axis, their overall drug profile varies (Table 2). Hence, these differences offer a unique role for each of the drug groups in the treatment algorithm for T2DM.

\section{SAFETY AND ADVERSE EVENTS WITH INCRETIN BASED THERAPY}

The most common side effect with GLP-1RA is nausea and, occasionally, vomiting. The frequency of gastrointestinal adverse events is less pronounced with DPP-4 inhibitors. Generally symptoms diminish over time. Some patients have reported diarrhea with GLP-1RA. Post-marketing cases of acute pancreatitis in patients treated with exenatide and acute pancreatitis in patients treated with liraglutide in clinical trials have led to amended label precautions for these agents. Similar case reports with sitagliptin (88 cases reported to the Food and Drug Administration [FDA] between October 2006 and February 2009) have been reported. However, patients with T2DM have a three-fold increased risk of pancreatitis compared with individuals who do not have diabetes. ${ }^{24}$ In summary, the data so far does not establish causality in terms of the use of incretinbased therapy, and a possible increase incidence in pancreatitis. However, a precautionary note is now included in all the drug labels and also warrants appropriate patient education.

Thyroid neoplasia preclinical rodent studies with liraglutide have shown an increase in C-cell thyroid cancer, which so far has not been demonstrated in monkeys or humans. ${ }^{25}$ Based on the preclinical studies in rodents, the FDA has requested a boxed warning for liraglutide, which includes contraindications for use in “...patients with a personal or family history of medullary thyroid carcinoma (MTC) or in patients with Multiple Endocrine Neoplasia syndrome type 2 (MEN 2)."25 Recent findings from a large screening study in 5000 subjects treated with liraglutide did not support an effect of GLP-1 receptor activation on serum calcitonin levels in humans, as reported in rodent studies. ${ }^{26}$ However, ongoing studies are evaluating the long-term safety of incretinbased therapy.

Other adverse events include hypoglycemia, particularly when GLP-1RA are used in conjunction with other $\mathrm{OAD}$, especially secretagogs. Injection site-related adverse events, such as itching and skin rashes, have also been reported. Less commonly, allergic reactions have been reported. Since 2009, the FDA required the possible associations between the use of exenatide and altered renal function to be highlighted in the prescribing information.

The optimal role of incretin-based therapies is still emerging. However, given their unique pharmacological properties, it is imperative that we explore further their changing roles within our treatment algorithms for T2DM. Most studies to date have assessed incretin-based 
Table 2. Comparing different types of incretin based therapy.

\begin{tabular}{lll}
\hline & $\begin{array}{l}\text { GLP-1 receptor agonists } \\
\text { (incretin mimetics) }\end{array}$ & $\begin{array}{l}\text { DPP-4 inhibitors } \\
\text { (incretin enhancers) }\end{array}$ \\
\hline Mode of action & $\begin{array}{l}\text { Increased receptor signaling, results } \\
\text { in pharmacological levels of GLP-1, } \\
\text { specific effect and hence results in extra- } \\
\text { pancreatic effects such weight loss and } \\
\text { delayed gastric emptying }\end{array}$ & $\begin{array}{l}\text { Increased levels of circulating GLP-1; non- } \\
\text { specific, limited by endogenous secretion }\end{array}$ \\
& $\begin{array}{l}\text { Parenteral (subcutaneous injection) } \\
\text { Route of delivery }\end{array}$ & Oral \\
HbA ${ }_{1 \mathrm{C}}$ reduction & $\begin{array}{l}\text { Induces weight loss } \\
\text { Effects on weight }\end{array}$ & 0.5\% to 1.1\% \\
Side effects & Increased GI symptoms, potentially & Weight neutral \\
& increased propensity to cause & $\begin{array}{l}\text { Fewer GI side effects and comparatively reduced } \\
\text { risk of iatrogenic hypoglycemia }\end{array}$ \\
\hline
\end{tabular}

DPP-4=dipeptidyl peptidase-4; GI=gastrointestinal; GLP-1=glucagon-like peptide-1; $\mathrm{HbA}_{1 \mathrm{C}}=$ hemoglobin A1c.

therapies as monotherapy or in combination with standard OADs. ${ }^{5,22}$ Accordingly, a growing number of treatment guidelines now incorporate incretin-based therapies, generally suggesting their consideration as add-ons to metformin or metformin plus other OAD combination therapy, and before resorting to insulin. ${ }^{2}$

Exenatide has also been compared with insulin therapy as an add-on to OAD. Heine et al. $^{27}$ compared response to addition of exenatide (10 $\mu$ g b.i.d.) versus insulin glargine (titrated to target fasting plasma glucose [FPG] of $<5.6 \mathrm{mmol} / \mathrm{L}$ ) in sub optimally controlled T2DM with metformin and/or sulfonylurea. At the end of the 26-week period both exenatide and insulin glargine reduced hemoglobin $\mathrm{A} 1 \mathrm{c}\left(\mathrm{HbA}_{1 \mathrm{c}}\right)$ levels by $1.11 \%$ (difference, 0.017 percentage point [95\% CI -0.123 to 0.157 percentage point]). Exenatide reduced postprandial glucose excursions more than insulin glargine, while insulin glargine reduced fasting glucose concentrations more than the exenatide group. In addition, subjects in the exenatide group lost an average of $2.3 \mathrm{~kg}$, but also showed a higher incidence of gastrointestinal side effects. On the other hand, the glargine group had lower
FPG levels, but with an average weight gain of $1.8 \mathrm{~kg}$. There were similar rates of hypoglycemia in both groups; nocturnal hypoglycemia was less common in the exenatide group (0.9 event/ patient-year versus 2.4 events/patient-year; difference, -1.6 events/patient-year [CI, -2.3 to -0.9 event/patient year]).

Exenatide has also been compared with biphasic insulin aspart. ${ }^{28}$ In a 52-week randomized control trial, glycemic control achieved with exenatide was non-inferior to that achieved with biphasic insulin aspart (mean \pm standard error of mean $[\mathrm{SEM}], \mathrm{HbA}_{1 \mathrm{c}}$ change: exenatide $-1.04 \pm 0.07 \%$, biphasic insulin aspart $-0.89 \pm 0.06 \%$; difference -0.15 [95\% CI -0.32 to 0.01$] \%)$. The exenatide group showed a weight reduction of $2.5 \mathrm{~kg}$, while the biphasic insulin group had a weight increase of $2.9 \mathrm{~kg}$. Liraglutide has shown favorable effects on glycemic control in comparison to insulin glargine (significant $\mathrm{HbA}_{1 \mathrm{c}}$ reduction [liraglutide vs glargine] $1.33 \%$ vs $1.09 \% ;-0.24 \%$ difference, 95\% CI 0.08, 0.39; $P=0.0015)$ and placebo (-1.09\% difference, 95\% CI 0.90, 1.28; $P<0.0001)$ in the 26-week randomized Liraglutide Effect and Action in Diabetes (LEAD)-5 trial. ${ }^{29}$ 
There was greater weight loss with liraglutide versus placebo (treatment difference $-1.39 \mathrm{~kg}$, 95\% CI 2.10, 0.69; $P=0.0001$ ), and versus glargine (treatment difference $-3.43 \mathrm{~kg}, 95 \%$ CI 4.00 , 2.86; $P<0.0001$ ).

Furthermore, the phase 3 Diabetes Therapy Utilization: Researching Changes in A1C, Weight and Other Factors Through Intervention With Exenatide Once Weekly (DURATION-3) trial compared once weekly exenatide against glargine. ${ }^{30}$ In this 26-week, open-label, randomized, parallel study, exenatide was compared with insulin glargine in adults with suboptimally controlled T2DM, despite using the maximum tolerated doses of OADs for 3 months or longer. Investigators randomly allocated 456 patients to treatment, who were included in the modified intention-to-treat analysis (233 exenatide, 223 insulin glargine). The change in $\mathrm{HbA}_{1 \mathrm{c}}$ at 26 weeks was greater in patients taking exenatide $(n=228 ;-1.5 \%$, standard error [SE] 0.05) than in those taking insulin glargine $(n=220 ;-1.3 \%, 0.06$; treatment difference $-0.16 \%, 0.07,95 \%$ CI -0.29 to -0.03 ). A planned extension period (up to 2.5 years' duration) is in progress. ${ }^{30}$

Given the evidence, incretin-based therapy in T2DM now appears to be well established as the second- or third-line agents prior to initiation of insulin. ${ }^{2,31}$ However, there are arguments for the adoption of incretin-based therapies earlier in the natural history of T2DM. Since GLP-1 acts as an insulin secretagog, incretin-based therapies are likely to have their optimal effect, while beta-cell function is preserved. There is also evidence from in vitro and animal studies that these agents could preserve beta-cell mass and function, and hence, potentially slow or halt disease progression. ${ }^{16,17}$ Moreover, there is increasing interest in using the incretins in combination with exogenous insulin therapy. The next section reviews the potential clinical role of such regimens, given the pathophysiology of T2DM.

\section{Future Role For Incretin Therapy}

Hyperglycemia in T2DM typically manifests initially as elevated postprandial glycemia (PPG), followed by fasting hyperglycemia. ${ }^{32,33}$ Furthermore, postprandial insulin secretion is greatly influenced by the incretin system, and the incretin system appears to be impaired in T2DM. Moreover, glucagon secretion is inappropriately elevated in T2DM. Hence, hepatic glucose output is increased, contributing to both postprandial and fasting hyperglycemia. ${ }^{34,35}$ It is, therefore, logical that treatment of T2DM should ideally address the ensuing PPG excursions as well as fasting hyperglycemia. The incretin system is clearly adapted (in normal physiology) to participate in the regulation of nutrient ingestion and disposal in general, and to help limit PPG excursions in particular. Thus, incretin-based therapies should prove helpful in this respect and more effective than traditional OADs, which do not directly address or effectively curtail PPG. Moreover, traditional insulin secretagogs (notably the SU) cannot improve PPG by enhancing alpha-cell function. ${ }^{36}$

PPG can, of course, be addressed by the use of short-acting mealtime insulins, but these carry a higher risk of hypoglycemia than basal insulin, ${ }^{37,38}$ and their use requires frequent injection and glucose monitoring. Short-acting insulin also requires patients to eat to 'counter their insulin', which compromises weight management. Consequently, in T2DM, basal-only insulin supplementation added to metformin (and sometimes other OADs) has gained popularity, particularly in primary care, as a simple and tolerable approach to initiating insulin therapy. ${ }^{39}$ This is arguably 
vindicated by the Treating to Target in Type 2 Diabetes (4T) study in which the choice of a basal-only insulin initiation regimen (using insulin detemir) resulted in a lower cumulative burden of hypoglycemia and weight gain, but similar $\mathrm{HbA}_{1 \mathrm{c}}$ achievement after 3 years when compared to insulin initiation with either prandial or premixed insulin products. ${ }^{38}$ Although basal insulin supplementation does not directly address PPG, it carries a low risk of hypoglycemia and may help to rest the beta-cell and relieve glucotoxicity, thereby potentially allowing partial recovery of the endogenous prandial insulin response. ${ }^{39-41}$ However, with further disease progression, basal insulin alone often proves insufficient to maintain control of $\mathrm{HbA}_{1 \mathrm{c}}$, obliging the addition of prandial insulins. The $4 \mathrm{~T}$ study illustrated this point by showing that a high percentage of patients commencing treatment with basal insulin required intensification of their initial regimen $67.7 \%$ in the biphasic group, $73.6 \%$ in the prandial group, and $81.6 \%$ in the basal group; $P=0.002$ for the overall comparison) within the 3-year study period..$^{38}$

An alternative to adding bolus insulins to basal insulin might be to combine basal insulin with an incretin since the latter glucosedependently maximize the preserved prandial insulin response while reducing glucagon levels in the setting of hyperglycemia. This would be particularly applicable to either a short acting GLP-1 receptor agonist (eg, exenatide) or a DPP-4 inhibitor. Studies comparing such combinations of incretin-based therapy have been mentioned further on (Table 3A and 3B). Placebo-controlled clamp studies have shown that both GLP-1 receptor agonists (exenatide ${ }^{11}$ ) and DPP-4 inhibitors (vildagliptin ${ }^{10}$ ) reduce glucagon secretion in conditions of hyperglycemia or euglycemia, yet increase glucagon output during hypoglycemia. Irrespective of the mechanism, the observation of an enhanced counterregulatory response is consistent with clinical reports of low hypoglycemia rates with these drugs, 5,22 and opens up the fascinating prospect of an incretin plus insulin regimen providing superior glucose control with a lower risk of hypoglycemia than an insulin regimen without incretin.

Another argument supporting this concept is that incretin-based therapies (particularly GLP-1RA) added to plus basal insulin could negate the weight gain associated with insulin that can arise through a number of potential mechanisms - including the retention of previously excreted glucose and an inappropriately high exposure of adipocytes to insulin after systemically administered. ${ }^{42}$ This offers the prospect of improved glycemia without weight gain. Finally, it is important to note that current practice is to maintain metformin in insulin-treated T2DM, and this approach is compatible with additional incretin therapy. As well as directly inhibiting hepatic glucose and increasing tissue sensitivity to insulin, ${ }^{43}$ metformin also increases GLP-1 levels. ${ }^{44}$ This increase follows metforminmediated increased GLP-1 production ${ }^{45}$ and DPP-4 inhibition. ${ }^{46,47}$ Thus, metformin is likely to act additively or synergistically with both DPP-4 inhibitors and GLP-1 derivatives. Indeed, DPP-4 inhibitors have been found to be significantly more effective when combined with metformin than when introduced as monotherapy in previously drug-naive patients. ${ }^{48,49}$ Hence, fixed-combination products are now available. In short, a regimen of incretin-based therapy plus basal insulin could mimic the pharmacological benefits of basal-bolus insulin therapy, but without the attendant calorie counting, and the associated risks of hypoglycemia and weight gain (Table 4). 
Table 3. Studies comparing combination of insulin with incretin-based therapies.

\begin{tabular}{|c|c|c|c|c|}
\hline Study & Design & Patients $(n)$ & Duration & Results \\
\hline \multicolumn{5}{|l|}{ GLP-1 based } \\
\hline $\begin{array}{l}\text { Yoon et al. } \\
2009^{50}\end{array}$ & $\begin{array}{l}\text { Retrospective analysis, } \\
\text { heterogeneous group; mean } \\
\text { baseline } \mathrm{HbA}_{1 \mathrm{C}} 8.05 \% \text {. } \\
\text { Exenatide added to insulin } \\
\text { (different regimes). }\end{array}$ & 188 & $\begin{array}{l}27 \text { months } \\
\text { (split } \\
\text { in four } \\
\text { intervals) }\end{array}$ & $\begin{array}{l}\text { Sustained } \mathrm{HbA}_{1 \mathrm{C}} \text { reduction } \\
\text { Initial weight loss, maximum mean } \\
\text { loss of } 6.2 \mathrm{~kg}(P<0.001) \text { from baseline } \\
\text { in } 12-18 \text { month interval. Adverse } \\
\text { effects - mainly GI (mild). Two } \\
\text { serious adverse events: } 1 \text { ) acute renal } \\
\text { failure (one patient, not related to } \\
\text { exenatide); } 2 \text { ) acute pancreatitis (one } \\
\text { patient in one month after starting } \\
\text { exenatide). }\end{array}$ \\
\hline Buse et al. $2010^{51}$ & $\begin{array}{l}\text { Prospective placebo controlled, } \\
\text { randomized study; } 12 \text { years } \\
\text { duration of T2DM. } \\
\text { Addition of exenatide or } \\
\text { matched placebo or glargine } \\
(+/- \text { OAD). }\end{array}$ & 259 & 30 weeks & $\begin{array}{l}\mathrm{HbA}_{1 \mathrm{C}} \text { reduced by } 1.7 \% \text { from baseline } \\
(8.3 \%) \text { while in placebo group, } \mathrm{HbA}_{1 \mathrm{C}} \\
\text { reduced by } 1 \% \text { from baseline }(8.5 \% \text {; } \\
P<0.001 \text {, between treatments). Placebo } \\
\text { group showed } 1 \text { kg weight gain, while } \\
\text { exenatide group showed weight loss of } \\
1.8 \mathrm{~kg}(P=0.001 \text {, between treatments). } \\
\text { Significantly more GI side effects } \\
\text { in the exenatide group with nausea } \\
\text { experienced by } 41 \% \text { versus } 8 \% .\end{array}$ \\
\hline \multirow{13}{*}{$\begin{array}{l}\text { Arnolds et al. } \\
2010^{55} \\
\text { (both GLP-1 and } \\
\text { DPP-4 inhibitor } \\
\text { based) }\end{array}$} & Proof of concept study. & 48 & 4 weeks & The six-hour postprandial blood \\
\hline & Prospective, single centre study & & & glucose excursion was significantly \\
\hline & involving both GLP-1 analog & & & lower with both exenatide \\
\hline & and DPP-4 inhibitor. Assess & & & $(P=0.0036)$ and sitagliptin \\
\hline & post-prandial glycemic control & & & $(P=0.0008)$ compared to the non- \\
\hline & while comparing the response & & & incretin intervention group. $\mathrm{HbA}_{1 \mathrm{C}}$ \\
\hline & of addition of exenatide (5-10 & & & changed by $-1.9 \%$ (exenatide), \\
\hline & $\mu \mathrm{g}$ b.i.d.) or sitagliptin (100 mg & & & $-1.5 \%$ (sitagliptin) and by $-1.2 \%$ \\
\hline & o.d.) or no further treatment & & & in the non-intervention group. \\
\hline & to a regime of metformin and & & & Hypoglycaemia rates were low. \\
\hline & insulin glargine (titrated to & & & Weight loss was seen in the exenatide \\
\hline & fasting blood glucose target & & & group $(-0.9 \mathrm{~kg})$ and was significantly \\
\hline & $<5.6 \mathrm{mmol} / \mathrm{L})$ & & & $\begin{array}{l}\text { different to a slight gain in the non- } \\
\text { incretin group }(+0.4 \mathrm{~kg}, P=0.0377)\end{array}$ \\
\hline
\end{tabular}

DPP-4 inbibitor

\section{based}

\begin{tabular}{lll}
\hline Fonseca et al. & $\begin{array}{l}\text { Prospective placebo controlled, } 296 \\
\text { randomized study, mean }\end{array}$ & 24 weeks \\
duration 14.7 years of T2DM, & $\begin{array}{l}\text { Mean } \mathrm{HbA}_{1 \mathrm{C}} \text { change: }-0.5 \% \text { in the } \\
\text { vildagliptin group and }-0.2 \% \text { in the } \\
\text { mean } \mathrm{HbA}_{1 \mathrm{C}} 8.4 \% \text { on high dose } \\
\text { insulin with average three }\end{array}$ & $\begin{array}{l}\text { placebo group }(P=0.01 \text { between } \\
\text { treatments difference). No difference }\end{array}$ \\
& in adverse events rate between both
\end{tabular}




\begin{tabular}{ll} 
Study & Design \\
\hline Fonseca et al. & injections/day. Randomized to \\
$2007^{52}$ & receive 50 mg b.i.d. of vildagliptin \\
(cont.) & or matched placebo.
\end{tabular}

Rosenstock et al. Prospective, placebo-controlled, 390 $2009^{53}$ randomized study. Mean duration of T2DM 12-13 years with baseline $\mathrm{HbA}_{1 \mathrm{C}}$ of $9.3 \%$. Once daily alogliptin $(12.5 \mathrm{mg}$ or $25 \mathrm{mg}$ ) or placebo added to insulin therapy $+/$ - metformin. No change in insulin dose.

Vilsboll et al. Prospective placebo controlled $2009^{54}$

Fonseca et al. $2008^{67}$

Patients $(n)$ Duration Results

groups. Both mild (1.95 vs 2.96 events/ patient/year, $P<0.01)$ and severe hypoglycemia ( 0.0 vs 0.1 events/ patient $/$ year, $P<0.05)$ were less common in the vildagliptin group.

26 weeks $\quad \mathrm{HbA}_{1 \mathrm{C}}$ change: $-0.63 \%$ with 12.5 and $-0.71 \%$ with $25 \mathrm{mg}$ of alogliptin versus $-0.13 \%$ with placebo; $P<0.001)$. No difference in reported hypoglycemia.

24 weeks $\quad \mathrm{HbA}_{1 \mathrm{C}}$ changed by $-0.6 \%$ in the sitagliptin group with no change in the placebo group $(P<0.001)$ Hypoglycemia was more common with sitagliptin. No significant change in body weight.

52 weeks Patients on $50 \mathrm{mg}$ b.i.d. of vildagliptin from the original study showed sustained $\mathrm{HbA}_{1 \mathrm{C}}$ reduction (-0.5\%). Those who switched from placebo to vildagliptin $50 \mathrm{mg}$ o.d. showed mean reduction of $-0.4 \%$. Weight remained stable.

\begin{tabular}{|c|c|c|c|c|}
\hline Study & Design & Patients $(n)$ & Duration & Results \\
\hline \multicolumn{5}{|l|}{ GLP-1 based } \\
\hline $\begin{array}{l}\text { Riddle et al. } \\
2010^{56}\end{array}$ & $\begin{array}{l}\text { Pilot study, mean duration of } \\
\text { T2DM } 8.5 \text { years on metformin } \\
\text { plus exenatide } 10 \mu \mathrm{g} \text { b.i.d. for } \\
\text { an } 8 \text { week run up period. Later } \\
\text { randomized (blinded) to receive } \\
\text { glargine with exenatide or } \\
\text { glargine with placebo instead of } \\
\text { exenatide. }\end{array}$ & 38 & $\begin{array}{l}32 \text { weeks } \\
\text { (including } 8 \\
\text { weeks run- } \\
\text { up period) }\end{array}$ & $\begin{array}{l}\mathrm{HbA}_{1 \mathrm{C}} \text { reduced from } 7.8 \% \text { to } 7.3 \% \text { in } \\
\text { the placebo group (glargine only) while } \\
\text { reduced to } 6.45 \% \text { in those continued } \\
\text { on exenatide ( } P=0.06 \text { between } \\
\text { groups). Greater proportion of patients } \\
\text { continuing exenatide reached } \mathrm{HbA}_{1 \mathrm{C}} \\
<7 \% \text { ( } 76 \% \text { versus } 24 \%, P=0.003 \text { ) } \\
\text { Weight increased by } 4.1 \mathrm{~kg} \text { in the } \\
\text { placebo group (discontinued }\end{array}$ \\
\hline
\end{tabular}




\begin{tabular}{|c|c|c|c|c|}
\hline Study & Design & Patients $(n)$ & Duration & Results \\
\hline Riddle et al. & & & & exenatide) and by $0.4 \mathrm{~kg}$ gain in those \\
\hline \multirow[t]{2}{*}{$2010^{56}$ (cont.) } & & & & on combination therapy. No severe \\
\hline & & & & hypoglycaemic events. \\
\hline \multirow{6}{*}{$\begin{array}{l}\text { Blevins et al. } \\
2010^{57}\end{array}$} & Prospective study, addition & 339 & 24 weeks & $\mathrm{HbA}_{1 \mathrm{C}}$ decreased by $1.16 \%$ in \\
\hline & of glargine or insulin lispro & & & the lispro group and by $1.40 \%$ in \\
\hline & (protaminated) to exenatide & & & the glargine group with modest \\
\hline & (used $>3$ months) plus OAD. & & & weight gain $(+0.3 \mathrm{~kg}$ and $+0.7 \mathrm{~kg}$ \\
\hline & Mean duration of T2DM 9.9 & & & respectively). \\
\hline & years with mean $\mathrm{HbA}_{1 \mathrm{C}}$ of $8.2 \%$ & & & \\
\hline \multirow{9}{*}{$\begin{array}{l}\text { Levin et al. } \\
2010^{68}\end{array}$} & Retrospective audit, data from & Glargine (93) & - & $\mathrm{HbA}_{1 \mathrm{C}}$ reduction varied, as did the \\
\hline & 20 clinical practices. Effect & - mean age 65 & & baseline control. Changes of $-1.51 \%$ \\
\hline & of adding glargine, exenatide & years. & & (glargine, baseline $9.2 \%$ ), $-0.86 \%$ \\
\hline & or the combination of two to & Exenatide & & (exenatide, baseline $8.2 \%$ ) and $-0.81 \%$ \\
\hline & OAD was assessed. & $(150)$ - mean & & (combination, baseline $8.5 \%$ ). The \\
\hline & & age 59 years. & & glargine only group gained $1.3 \mathrm{~kg}$ ) \\
\hline & & Combination & & while those on exenatide, alone $(-3.25$ \\
\hline & & $(74)$ - mean & & $\mathrm{kg})$ or in combination $(-2.65 \mathrm{~kg})$ lost \\
\hline & & age 60 years. & & weight. \\
\hline \multirow{2}{*}{\multicolumn{5}{|c|}{ DPP-4 inbibitor }} \\
\hline & & & & \\
\hline \multirow{12}{*}{$\begin{array}{l}\text { TRANSITION } \\
\text { study } 2011^{69}\end{array}$} & Prospective study in insulin-naïve & 217 & 26 weeks & $\mathrm{HbA}_{1 \mathrm{C}}$ changed by $-1.44 \%$ with \\
\hline & patients. Compared simultaneous & & & detemir plus sitagliptin and $-0.89 \%$ \\
\hline & addition of sitagliptin plus insulin & & & with sitagliptin +/- SU $(P<0.001 \%)$ \\
\hline & detemir (with discontinuation of & & & FPG levels were significantly lower in \\
\hline & $\mathrm{SU})$ to introduction of sitagliptin & & & the group on detemir with sitagliptin \\
\hline & alone with SU continued. & & & (FPG decreased by $3.7 \mathrm{mmol} / \mathrm{l}$ )than \\
\hline & Metformin was continued for & & & with sitagliptin +/- sulphonylurea (FPG \\
\hline & both groups. Mean $\mathrm{HbA}_{1 \mathrm{C}}$ of & & & decreased by $1.2 \mathrm{mmol} / \mathrm{L} ; P<0.001)$. \\
\hline & $8.5 \%$ on metformin and SU. & & & Self-monitored plasma glucose profiles \\
\hline & & & & suggested that 2-hour postprandial \\
\hline & & & & glucose levels were significantly lower \\
\hline & & & & with detemir plus sitagliptin. \\
\hline
\end{tabular}

b.i.d.=twice daily; DPP-4= dipeptidyl peptidase-4; FPG=fasting plasma glucose; GI=gastrointestinal; GLP-1= glucagonlike peptide-1; $\mathrm{HbA}_{1 \mathrm{C}}=$ hemoglobin $\mathrm{A} 1 \mathrm{c} ; \mathrm{OAD}=$ o.d.=once daily; $\mathrm{SU}=$ sulfonylureas; T2DM-type 2 diabetes mellitus.

\section{Clinical Evidence Supporting Adding Incretin-Based Therapies to Basal Insulin}

Recent clinical studies allude to the advantage of adding incretin-based therapies to basal insulin, especially in terms of offsetting the associated weight gain as well as the reduction or neutrality in incidence of hypoglycemia. ${ }^{50-55}$ These effects are observed even when incretinbased therapies are added at a relatively later stage of disease. There have also been some studies assessing insulin added to incretin-based therapies. ${ }^{56,57}$ Data from these studies, albeit limited, demonstrates that a 
GLP-1RA can continue to make a major contribution to glucose lowering once insulin is introduced and supports yet another theoretically appealing treatment approach (Table 4).

On the other hand, there are pathophysiological and pharmacological arguments for introducing incretin therapies early in the disease process before insulin is needed. For example, the insulin-releasing effect of incretins is likely to decline with progressive beta-cell failure. A recent study in T2DM patients showed that the proinsulin: C-peptide ratio of a beta-cell response to GLP-1 is reduced following a period of near-normoglycemia with insulin treatment, ${ }^{58}$ implying that the insulinotropic effect of GLP-1 is more efficient when betacells are less stressed. Any ability to reverse or preserve beta-cell mass is also likely to decline with disease progression. ${ }^{16}$

As incretin and insulin therapy becomes more widely used, many more studies will be published. At present, however, with the exception of the Arnolds et al. pilot study, ${ }^{55}$ we lack any trials that directly compare alternative incretin therapies in combination with insulin or alternative insulins combined with an incretin therapy. Nevertheless, the evidence so far suggests that GLP-1RA are more effective at mitigating insulin-associated weight gain and generally tend to provide somewhat greater reductions in hyperglycemia than DPP-4

Table 4. Benefits of introducing incretin therapy before establishing patients on insulin.

Potentially delay or avert the need for insulin

Low risk of hypoglycemia in comparison to insulin therapy

Weight gain associated with insulin initiation might be minimized by established incretin therapy

Tolerance to nausea is established before insulin is introduced inhibitors. Both liraglutide ${ }^{59}$ and extended release exenatide ${ }^{60}$ have been shown to lower $\mathrm{HbA}_{1 \mathrm{c}}$ and reduce weight to a greater extent than sitagliptin when added to metformin.

However, possible tolerability advantages for the DPP-4 inhibitors, such as their oral administration and a reduced likelihood of nausea and, perhaps, hypoglycemia, ${ }^{5}$ must be weighed against these efficacy advantages of the GLP-1RA. Such issues and the relative performances of incretin plus basal insulin regimens versus basal plus bolus insulin regimens at various stages in the T2DM disease process require testing in future trials. It would also be interesting to study the effects of combination of DPP-4 inhibitors with GLP-1RA, with and without insulin. DPP-4 plays a role in the metabolism of at least some of the GLP-1RA, such as liraglutide; ${ }^{61}$ the two drug types could potentially be combined synergistically.

It is also unclear how the efficacy of various incretin plus insulin regimens will change longitudinally in the course of the T2DM disease process, and hence, whether and how we will need to adapt dosing. Some data, mostly preclinical, had suggested that prolonged stimulation of GLP-1 receptors might cause desensitization. ${ }^{62}$ The effects studied on islet cells, however, did not translate into clinical desensitization in vivo. Recently, there has also been some human data published in line with GLP-1 receptor desensitization and possible tachyphylaxis. ${ }^{63}$ Nauck and colleagues ${ }^{63}$ administered native GLP-1 continuously for 8.5 hours to healthy human subjects without T2DM, and assessed the glucoregulatory responses to liquid test-meals given 5 hours apart with ongoing continuous GLP-1 infusion. The ability of GLP-1 to inhibit gastric emptying and glucagon levels was significantly reduced by the second test meal. However, C-peptide and insulin levels were preserved but slightly diminished 
with the second meal. Levels of pancreatic polypeptide, a marker of vagal activation, were not as inhibited during the second test meal. Hence, even short-term continuous GLP-1 receptor stimulation may be association with some degree of rapid tachyphylaxis, mostly evident in effects mediated through the vagus nerve and gastric emptying. ${ }^{63}$

Immunogenicity is another factor which may potentially affect the efficacy of intecrin-based therapies, affecting especially GLP-1RA. Most of the data around antibodies is based on the findings of the LEAD- 6 and DURATION-1 trials.64,65 LEAD-6 was a 26-week trial comparing exenatide $10 \mu \mathrm{g}$ b.i.d. against liraglutide $1.8 \mathrm{mg}$ o.d. with a 52 week extension period following switch over from exenatide to liraglutide therapy. ${ }^{64}$ DURATION-1 compared exenatide $10 \mu \mathrm{g}$ b.i.d. against once weekly exenatide long-acting release (LAR) ( $2 \mathrm{mg}$ ) over 30 weeks. ${ }^{65}$ High titers were noted for antibodies against exenatide $(61 \%$ at week $26)$, whereas low titers were observed for antiliraglutide antibodies $(2.6 \%$ at week 79 of continued liraglutide therapy, 3\% at week 79 in group switched from exenatide to liraglutide in week 26). ${ }^{64}$ After the switch from exenatide to liraglutide, the percentage of patients with antiexenatide antibodies decreased to approximately $18 \%$ by the end of the 78 weeks. ${ }^{64}$ The presence of persistent anti-exenatide antibodies did not appear to compromise glycemic response. On the contrary, patients with the highest titers of anti-exenatide antibodies also had the greatest reduction in $\mathrm{HbA}_{1 \mathrm{C}}{ }^{64}$ In DURATION-1, antiexenatide antibody levels were higher with exenatide taken once a week $(P=0.0002$ vs exenatide b.i.d.); however, most antibodies were either not detectable or of low $(<1 / 625)$ titre. ${ }^{65}$ Despite the presence of higher antibody titers, a significantly greater reduction in $\mathrm{HbA}_{1 \mathrm{C}}$ (1.9\%) was observed in the exenatide LAR group in comparison to the exenatide b.i.d. group. ${ }^{65}$ Therefore, based on the findings of head-to-head trials, antibody generation was more pronounced for exenatide LAR and less with liraglutide. Overall, liraglutide is less immunogenic than exenatide and antibody titers do not appear to affect glycemic efficacy or safety. ${ }^{64}$

Another related question is whether there is a continuing role for incretin therapies when prandial insulin becomes necessary. An ongoing effect on alpha-cell function would imply that there could be a useful role for incretin therapies in late-stage T2DM and even type 1 diabetes. ${ }^{66}$ The prospect of prolonged use of incretin therapies also requires us to study the long-term safety profiles of these agents and regimens. Many useful new insights are likely to emerge from epidemiological and observational studies, as well as those expected from the randomized trials currently in progress. In addition, and most importantly, data in terms of hard cardiovascular endpoints with prolonged use of incretin-based therapy, have yet to accumulate.

\section{Where and When Should We Use Incretin- Based Therapy Plus Insulin?}

Treatment guidelines currently position incretinbased therapies and insulin after conventional OAD, but from what we know of T2DM pathophysiology and the pharmacology of the incretin therapies, current practices may not produce optimal results. We believe that evidence so far supports the combined use of incretins and insulin early in the T2DM disease process, albeit in selected patients. However, the biggest challenge would be selecting the right group of patients who would derive the maximum benefit from such a combination. In addition, the timing of implementing incretinbased therapy with insulin would be a major 
determinant of treatment efficacy. Given that progressive beta-cell decline characterizes the natural history of T2DM and given the dependence of incretin-based therapies on endogenous insulin production, it would be prudent to initiate therapy while there is still some beta-cell function remaining. However, to ascertain this in a clinical setting would present a big challenge. Furthermore, there is a lack of clinical data correlating efficacy of incretin-based therapy with declining betacell function. In addition, there is little robust data in terms of long-term safety and effect on hard cardiovascular endpoints with incretinbased therapy. Similarly, there is insufficient clinical evidence to substantiate potential role of incretin-based therapy in increasing beta-cell mass and altering T2DM progression.

In our opinion, incretin plus basal insulin therapy has a logical rationale and may provide excellent efficacy and tolerability in the treatment of T2DM for a very selective group of patients. It is, perhaps, better to start with an incretin-based agent and then add insulin rather than vice versa as this avoids the complexity of having to down-titrate insulin, and any nausea issues with GLP-1RA are likely to have subsided with this sequence. While we advocate the introduction of incretin-based therapy prior to insulin, we also stress that patients suboptimally controlled on high-dose basal insulin can nevertheless benefit from the addition of an incretin. Given the evidence from combination studies, a DPP-4 inhibitor at mealtime with basal/premixed insulin or a short acting GLP-1 receptor agonists (b.i.d. or o.d.) with basal/premixed insulin might be preferred. Once again, due to lack of evidence so far, selecting patients who would benefit from such a combination would be dependent on the clinician's expertise. Finally, given the paucity of data, it would be difficult to predict the role of longer acting GLP-1RA such as exenatide LAR, in such combination therapy.

\section{CONCLUSION}

In summary, data from initial studies looking at a combination of insulin and incretin-based therapy are promising. Though several questions still remain to be answered, there is already evidence to advocate this tactic in patients who are not contraindicated and who have reached the point of requiring intensification from metformin \pm other OAD or metformin plus basal-only insulin. The cost of incretin-based therapy, however, remains a major limiting factor, especially in the United Kingdom where healthcare is still primarily state funded. This is particularly pertinent in the current economic climate. Therefore, and in the absence of longterm safety data, it would be prudent to exercise caution with the use of an incretin-based therapy.

\section{ACKNOWLEDGMENTS}

Dr R Ahluwalia declares that has no conflicts of interest. Professor J Vora was a member of the panel of the guideline development group for the NICE guidance for type 2 diabetes- newer agents (partial update) but has no further conflicts of interest. Dr Ahluwalia is the guarantor for this article, and takes responsibility for the integrity of the work as a whole.

Open Access. This article is distributed under the terms of the Creative Commons Attribution Noncommercial License which permits any noncommercial use, distribution, and reproduction in any medium, provided the original author(s) and source are credited. 


\section{REFERENCES}

1. DeFronzo RA. Pathogenesis of type 2 diabetes mellitus. Med Clin North Am. 2004; 88:787-835.

2. Nathan DM, Buse JB, Davidson MB, et al. Medical management of hyperglycaemia in type 2 diabetes: a consensus algorithm for the initiation and adjustment of therapy. A consensus statement of the American Diabetes Association and the European Association for the Study of Diabetes. Diabetologia. 2009;52:17-30.

3. Holman R. Metformin as first choice in oral diabetes treatment: the UKPDS experience. J Annu Diabetol Hotel Dieu. 2007:13-20.

4. Hermansen K, Mortensen LS. Bodyweight changes associated with antihyperglycaemic agents in type 2 diabetes mellitus. Drug Saf. 2007;30:1127-1142.

5. Drucker DJ, Nauck MA. The incretin system: glucagon-like peptide-1 receptor agonists and dipeptidyl peptidase-4 inhibitors in type 2 diabetes. Lancet. 2006;368:1696-1705.

6. Nauck M, Stockmann F, Ebert R, Creutzfeldt W. Reduced incretin effect in type 2 (non-insulindependent) diabetes. Diabetologia. 1986;29:46-52.

7. Nauck MA, Heimesaat MM, Orskov C, Holst JJ, Ebert R, Creutzfeldt W. Preserved incretin activity of glucagon-like peptide 1 [7-36 amide] but not of synthetic human gastric inhibitory polypeptide in patients with type- 2 diabetes mellitus. J Clin Invest. 1993;91:301-307.

8. Vilsbøll T, Krarup T, Madsbad S, Holst JJ. Defective amplification of the late phase insulin response to glucose by GIP in obese Type II diabetic patients. Diabetologia. 2002;45:1111-1119.

9. Meier JJ, Nauck MA. Is the diminished incretin effect in type 2 diabetes just an epi-phenomenon of impaired beta-cell function? Diabetes. 2010;59:1117-1125.

10. Ahrén B, Schweizer A, Dejager S, et al. Vildagliptin enhances islet responsiveness to both hyper- and hypoglycemia in patients with type 2 diabetes. J Clin Endocrinol Metab. 2009;94:1236-1243.

11. Degn KB, Brock B, Juhl CB, et al. Effect of intravenous infusion of exenatide (synthetic exendin-4) on glucose-dependent insulin secretion and counter regulation during hypoglycemia. Diabetes. 2004;53:2397-2403.
12. Wettergren A, Schjoldager B, Mortensen PE, Myhre J, Christiansen J, Holst JJ. Truncated GLP1 (proglucagon 78-107-amide) inhibits gastric and pancreatic functions in man. Dig Dis Sci. 1993;38:665-673.

13. Flint A, Raben A, Astrup A, Holst JJ. Glucagon-like peptide 1 promotes satiety and suppresses energy intake in humans. J Clin Invest. 1998;101:515-520.

14. Mudaliar S, Henry RR. Effects of incretin hormones on beta cell mass and function, body weight, and hepatic and myocardial function. Am J Med. 2010;123(Suppl. 3):S19-27.

15. Tews D, Werner U, Eckel J. Enhanced protection against cytokine- and fatty acid-induced apoptosis in pancreatic beta cells by combined treatment with glucagon-like peptide- 1 receptor agonists and insulin analogues. Horm Metab Res. 2008;40:172180.

16. Bosi E. Time for testing incretin therapies in early type 1 diabetes? J Clin Endocrinol Metab. 2010;95:2607-2609.

17. Drucker DJ. The biology of incretin hormones. Cell Metab 2006;3:153-165.

18. Nauck MA, Heimesaat MM, Behle K, et al. Effects of glucagon-like peptide 1 on counterregulatory hormone responses, cognitive functions, and insulin secretion during hyperinsulinemic, stepped hypoglycaemic clamp experiments in healthy volunteers. J Clin Endocrinol Metab. 2002; 87:1239-1246.

19. Chaudhri O, Small C, Bloom S. Gastrointestinal hormones regulating appetite. Philos Trans R Soc Lond B Biol Sci. 2006;361:1187-1209.

20. Barber TM, Begbie H, Levy J. The incretin pathway as a new therapeutic target for obesity. Maturitas. 2010;67:197-202

21. Richter B, Bandeira-Echtler E, Bergerhoff K, Lerch CL. Dipeptidyl peptidase-4 (DPP-4) inhibitors for type 2 diabetes mellitus. Cochrane Database Syst Rev. 2008:CD006739.

22. Bell TJ and Wright EE Jr. Can therapies that target the incretin system improve our ability to treat type 2 diabetes? J Natl Med Assoc. 2010;102:511523.

23. Neumiller JJ. Clinical pharmacology of incretin therapies for type 2 diabetes mellitus: implications for treatment. Clin Ther. 2011;33:528-576. 
24. Noel RA, Braun DK, Patterson RE, Bloomgren GL. Increased risk of acute pancreatitis and biliary disease observed in patients with type 2 diabetes: a retrospective cohort study. Diabetes Care. 2009;32:834-838.

25. Victoza (liraglutide [rDNA] injection) [prescribing information]. Princeton, New Jersey: Novo Nordisk Inc; 2011. Available at: http://www.novo-pi.com/ victoza.pdf. Last accessed June 7, 2011.

26. Hegedüs L, Moses AC, Zdravkovic M, Le Thi T, Daniels GH. GLP-1 and calcitonin concentration in humans: lack of evidence of calcitonin release from sequential screening in over 5000 subjects with type 2 diabetes or nondiabetic obese subjects treated with the human GLP-1 analog, liraglutide. J Clin Endocrinol Metab. 2011;96:853-860.

27. Heine RJ, Van Gaal LF, Johns D, Mihm MJ, Widel $\mathrm{MH}$, Brodows RG. Exenatide versus insulin glargine in patients with sub optimally controlled type 2 diabetes: a randomized trial. Ann Intern Med. 2005;143:559-569.

28. Nauck MA, Duran S, Kim D, et al. A comparison of twice-daily exenatide and biphasic insulin aspart in patients with type 2 diabetes who were suboptimally controlled with sulfonylurea and metformin: a non-inferiority study. Diabetologia. 2007;50:259-267.

29. Russell-Jones D, Vaag A, Schmitz O, et al. Liraglutide vs. insulin glargine and placebo in combination with metformin and sulfonylurea therapy in type 2 diabetes mellitus (LEAD -5 met+SU): a randomised controlled trial. Diabetologia 2009;52:2046-2055.

30. Diamant M, Van Gaal L, Stranks S, et al. Once weekly exenatide compared with insulin glargine titrated to target in patients with type 2 diabetes (DURATION-3): an open-label randomised trial. Lancet. 2010;375:2234-2243.

31. Type 2 diabetes-newer agents for blood glucose control in type 2 diabetes (partial update of CG66). National Institute for Health and Clinical Excellence (NICE). Short clinical guidance 87. May 2009.

32. Coates PA, Ollerton RL, Luzio SD, Ismail I, Owens DR. A glimpse of the 'natural history' of established type 2 (non-insulin dependent) diabetes mellitus from the spectrum of metabolic and hormonal responses to a mixed meal at the time of diagnosis. Diabetes Res Clin Pract. 1994;26:177-187.
33. Owens DR, Luzio SD, Coates PA. Insulin secretion and sensitivity in newly diagnosed NIDDM Caucasians in the UK. Diabet Med. 1996;13(9 Suppl. 6):S19-24.

34. Dunning BE, Foley JE, Ahrén B. Alpha cell function in health and disease: influence of glucagon-like peptide-1. Diabetologia. 2005;48:1700-1713.

35. Ahrén B. Beta- and alpha-cell dysfunction in subjects developing impaired glucose tolerance: outcome of a 12-year prospective study in postmenopausal Caucasian women. Diabetes. 2009;58:726-731.

36. Ahrén B, Foley JE, Ferrannini E, et al. Changes in prandial glucagon levels after a 2-year treatment with vildagliptin or glimepiride in patients with type 2 diabetes inadequately controlled with metformin monotherapy. Diabetes Care. 2010;33:730-732.

37. Holman RR, Thorne KI, Farmer AJ, et al. Addition of biphasic, prandial, or basal insulin to oral therapy in type 2 diabetes. $\mathrm{N}$ Engl J Med. 2007;357:1716-1730.

38. Holman RR, Farmer AJ, Davies MJ, et al. Threeyear efficacy of complex insulin regimens in type 2 diabetes. N Engl J Med. 2009;361:1736-47.

39. Meneghini L, Liebl A, Abrahamson MJ. Insulin detemir: a historical perspective on a modern basal insulin analogue. Prim Care Diabetes. 2010;4(Suppl. 1):S31-42.

40. Garvey WT, Olefsky JM, Griffin J, Hamman RF, Kolterman OG. The effect of insulin treatment on insulin secretion and insulin action in type II diabetes mellitus. Diabetes. 1985;34:222-234.

41. Li Y, Xu W, Liao Z, et al. Induction of long-term glycemic control in newly diagnosed type 2 diabetic patients is associated with improvement of beta-cell function. Diabetes Care. 2004;27:2597602.

42. Russell-Jones D, Khan R. Insulin-associated weight gain in diabetes - causes, effects and coping strategies. Diabetes Obes Metab. 2007;9:799-812.

43. Ahrén B. Novel combination treatment of type 2 diabetes DPP-4 inhibition + metformin. Vasc Health Risk Manag. 2008;4:383-394.

44. Mannucci E, Tesi F, Bardini G, et al. Effects of metformin on glucagon-like peptide- 1 levels in obese patients with and without Type 2 diabetes. Diabetes Nutr Metab. 2004;17:336-342. 
45. Migoya EM, Miller J, Larson P, et al. Sitagliptin, a selective DPP-4 inhibitor, and metformin have complementary effects to increase active GLP-1 concentrations. Diabetes. 2007;56(Suppl. 1):A74.

46. Green BD, Irwin N, Duffy NA, Gault VA, O'Harte FP, Flatt PR. Inhibition of dipeptidyl peptidase-IV activity by metformin enhances the antidiabetic effects of glucagon-like peptide-1. Eur J Pharmacol. 2006;547:192-199.

47. Cuthbertson J, Patterson S, O'Harte FP, Bell PM. Addition of metformin to exogenous glucagonlike peptide- 1 results in increased serum glucagonlike peptide- 1 concentrations and greater glucose lowering in type 2 diabetes mellitus. Metabolism. 2011;60:52-6. Epub 2010 Feb 11.

48. Goldstein BJ, Feinglos MN, Lunceford JK, Johnson J, Williams-Herman DE; Sitagliptin 036 Study Group. Effect of initial combination therapy with sitagliptin, a dipeptidyl peptidase- 4 inhibitor, and metformin on glycemic control in patients with type 2 diabetes. Diabetes Care. 2007;30:1979-1987.

49. Jadzinsky M, Pfützner A, Paz-Pacheco E, Xu Z, Allen E, Chen R; CV181-039 Investigators. Saxagliptin given in combination with metformin as initial therapy improves glycemic control in patients with type 2 diabetes compared with either monotherapy: a randomized controlled trial. Diabetes Obes Metab. 2009;11:611-622.

50. Yoon NM, Cavaghan MK, Brunelle RL, Roach P. Exenatide added to insulin therapy: a retrospective review of clinical practice over two years in an academic endocrinology outpatient setting. Clin Ther. 2009;31:1511-1523.

51. Buse JB, Bergenstal RM, Glass LC, et al. Use of twice-daily exenatide in basal insulin-treated patients with type 2 diabetes: a randomized, controlled trial. Ann Intern Med. 2011;154:103112.

52. Fonseca V, Schweizer A, Albrecht D, Baron MA, Chang I, Dejager S. Addition of vildagliptin to insulin improves glycemic control in type 2 diabetes. Diabetologia. 2007;50:1148-1155.

53. Rosenstock J, Rendell MS, Gross JL, Fleck PR, Wilson CA, Mekki Q. Alogliptin added to insulin therapy in patients with type 2 diabetes reduces HbA1C without causing weight gain or increased hypoglycemia. Diabetes Obes Metab. 2009;11: 1145-1152.
54. Vilsboll T, Rosenstock J, Yki-Jarvinen $\mathrm{H}$, et al. Efficacy and safety of sitagliptin when added to insulin therapy in patients with type 2 diabetes. Diabetes Obes Metab. 2010;12:167-177.

55. Arnolds S, Dellweg S, Clair J, et al. Further improvement in postprandial glucose control with addition of exenatide or sitagliptin to combination therapy with insulin glargine and metformin: a proof-of-concept study. Diabetes Care. 2010;33:1509-1515.

56. Riddle M, Ahmann A, Basu A, Aroda V, Ratner R. Metformin+exenatide+basal insulin vs. metformin+placebo+basal insulin: reaching a1c $<6.5 \%$ without weight-gain or serious hypoglycaemia (abstract). Diabetes. 2010;59(Suppl. 1A):LB18.

57. Blevins TC, Arakaki RF, Liljenquist DR et al. Oncedaily basal insulin added to oral antihyperglycemic medications (OAMs) and exenatide (Ex) improves glycaemic control in patients (Pts) with type 2 diabetes (T2D)(abstract). Diabetes. 2010;59(Suppl. 1A):LB19.

58. Asmar M, Højberg PV, Deacon CF, Hare K, Holst JJ, Madsbad S. Pancreatic beta-cell responses to GLP-1 after near-normalization of blood glucose in patients with type 2 diabetes. Regul Pept. 2010;160:175-180.

59. Pratley RE, Nauck M, Bailey T, et al. Liraglutide versus sitagliptin for patients with type 2 diabetes who did not have adequate glycemic control with metformin: a 26-week, randomised, parallel-group, open-label trial. Lancet. 2010; 375:1447-1456.

60. Bergenstal RM, Wysham C, Macconell L, et al. Efficacy and safety of exenatide once weekly versus sitagliptin or pioglitazone as an adjunct to metformin for treatment of type 2 diabetes (DURATION-2): a randomised trial. Lancet. 2010;376:431-439.

61. Malm-Erjefält M, Bjornsdottir I, Vanggaard J, et al. Metabolism and excretion of the once daily human GLP-1 analog liraglutide in healthy male subjects and its in vitro degradation by dipeptidyl peptidase IV and neutral endopeptidase. Drug Metab Dispos. 2010;38:1944-1953.

62. Baggio LL, Kim JG, Drucker DJ. Chronic exposure to GLP-1R agonists promotes homologous GLP1 receptor desensitization in vitro but does not attenuate GLP-1R-dependent glucose homeostasis in vivo. Diabetes. 2004;53(Suppl. 3):S205-214. 
63. Nauck MA, Kemmeries G, Holst JJ, Meier JJ. Rapid tachyphylaxis of the glucagon-like peptide-1induced deceleration of gastric emptying in humans. Diabetes. 2011;60:1561-1565.

64. Buse JB, Garber A, Rosenstock J, et al. Liraglutide treatment is associated with a low frequency and magnitude of antibody formation with no apparent impact on glycemic response or increased frequency of adverse events: results from the Liraglutide Effect and Action in Diabetes (LEAD) trials. J Clin Endocrinol Metab. 2011;96:1695-1702.

65. Drucker DJ, Buse JB, Taylor $\mathrm{K}$, et al. Exenatide once weekly versus twice daily for the treatment of type 2 diabetes: a randomised, open-label, noninferiority study. Lancet. 2008;372:1240-1250.

66. Foley JE, Ligueros-Saylan M, He YL, et al. Effect of vildagliptin on glucagon concentration during meals in patients with type 1 diabetes. Horm Metab Res. 2008;40:727-730.

67. Fonseca V, Baron M, Shao Q, Dejager S. Sustained efficacy and reduced hypoglycemia during one year of treatment with vildagliptin added to insulin in patients with type 2 diabetes mellitus. Horm Metab Res. 2008;40:427-430.

68. Levin P, Mersey JH, Zhou S, Bromberger L. Clinical outcomes using single vs. combination therapy with glargine (GLA) or exenatide (EX)(abstract). Diabetes. 2010;59(Suppl. 1):P652.

69. Hollander P, Raslova K, Skjoth TV, Råstam J, Liutkus JF. Efficacy and safety of insulin detemir once daily in combination with sitagliptin and metformin: the TRANSITION randomised controlled trial. Diabetes Obes Metab. 2011;13:268-275. 